\title{
The Difference of Subcellular Localization between $\beta$-Conglycinin and Glycinin in Developing Soybean Cotyledons
}

\author{
Michiko Monma, Toshio Sugimoto and Kyoko SAIO \\ National Food Research Institute, Ministry of Agriculture, \\ Forestry and Fisheries, Tsukuba, Ibaraki 305, Japan \\ Received October 7, 1987
}

\begin{abstract}
Subcellular localization of $\beta$-conglycinin and glycinin in developing soybean cotyledons was examined by sucrose density gradient ultracentrifugation (SDG-UC). Two major bands appeared at densities of 1.05 and 1.15 in the SDG-UC. They were the microbody fraction and rER fraction, respectively, from the distribution of marker enzymes, electron microscopic observation, and the effects of $\mathrm{MgCl}_{2}$ on the profile of SDG-UC. In the soluble and microbody fractions, $\alpha$ and $\alpha^{\prime}$ subunits of $\beta$-conglycinin were major polypeptides. The amounts of $\beta$-conglycinin and glycinin associated with rER were roughly equal. $\beta$-Conglycinin was found in the soluble and microbody fractions as well as the rER fraction while glycinin was mostly localized in the rER fraction.
\end{abstract}

The major storage proteins of soybean seeds are glycinin and $\beta$-conglycinin, which together make up $70 \%$ of the total protein of the mature seed. In the mature seed, these proteins are accumulated in protein bodies ${ }^{1)}$ in the cotyledon parenchyma cells. Soybean seeds synthesize and accumulate large amount of storage proteins in the course of their development. Their biosynthesis has been extensively investigated by many researchers ${ }^{2,3)}$ and fundamental mechanisms are already clear. However, it is still under argument how these storage proteins are intracellularly transported from the biosynthesis site, rER, to the deposition site, protein bodies. To help the understanding of the intracellular transport system of storage proteins in developing soybean seeds, we examined their subcellular localization in developing soybean cotyledons by SDG-UC. In this report we showed that glycinin and $\beta$-conglycinin are found in different organelles in developing cotyledons.

\section{MATERIALS AND METHODS}

Plant material. Soybean plants (Glycine max var. Enrei) were grown in pots during the summer season of 1985 . Developing seeds were harvested at $20 \sim 30 \mathrm{DAF}$ (weighed $0.2 \sim 0.3 \mathrm{~g} / \mathrm{seed})$.

Separation of organelles by sucrose density gradient ultracentrifugation. Developing cotyledons $(5.0 \mathrm{~g})$ were homogenized in a Petri dish placed in an ice bath by chopping with a stainless steel razor blade for $5 \mathrm{~min}$ using $20 \mathrm{ml}$ of chilled medium containing $25 \mathrm{~mm}$ HEPES-KOH (pH 7.2), 0 or $5 \mathrm{~mm} \mathrm{MgCl}_{2}, 1 \mathrm{~mm}$ EDTA, $5 \mathrm{~mm} 2-\mathrm{ME}$, $330 \mathrm{~mm}$ sorbitol, and $0.5 \%$ PVP. The homogenate was passed through four layers of cheesecloth and $4 \mathrm{ml}$ of the filtrate was put directly onto a sucrose gradient. The sucrose gradient contains $25 \mathrm{mM} \mathrm{HEPES}-\mathrm{KOH}$ (pH 7.2), 0 or $5 \mathrm{mM} \mathrm{MgCl}_{2}, 1 \mathrm{~mm}$ EDTA, and $1 \mathrm{~mm} 2-\mathrm{ME}$ and consists of a $1-\mathrm{ml}$ cushion of $70 \%(\mathrm{w} / \mathrm{w})$ sucrose and $12 \mathrm{ml}$ of $20 \sim 70 \%$ sucrose gradient in a $17-\mathrm{ml}$ tube. The gradient solution was then centrifuged at $24,000 \mathrm{rpm}$ for $3 \mathrm{hr}$ in a Beckman model L8-70 ultracentrifuge using an SW28 rotor at $4^{\circ} \mathrm{C}$. After the centrifugation, $0.75-\mathrm{ml}$ fractions were collected by a syringe. All fractions were used for the measurement of sucrose density and protein content and the assays of marker enzymes. Major bands of organelles in the SDG-UC were examined by electron microscopy and SDS-PAGE.

Abbreviations: SDG-UC, sucrose density gradient ultracentrifugation; SDS-PAGE, sodium dodecyl sulfate polyacrylamide-gel electrophoresis; DAF, days after flowering; rER, rough endoplasmic reticulum; EDTA, ethylenediaminetetraacetic acid; 2-ME, 2-mercaptoethanol; PVP, polyvinylpyrrolidone; MW, molecular weight. 
Analytical methods. The sucrose concentration of the fractions was measured with a Brix sugar analyzer. Protein content was estimated by a Coomassie Brilliant Blue binding method ${ }^{4}$ with bovine serum albumin for the standard protein. For enzyme assays $0.3 \mathrm{ml}$ of each fraction was mixed with an equal amount of $2 \%$ Triton $X-100$ to solubilize the enzymes. NADPH-cytochrome $c$ reductase and catalase activities were assayed as described by Lord et al. ${ }^{51}$ and Aebi, ${ }^{6)}$ respectively. For SDS-PAGE, $100 \mu \mathrm{l}$ of each fraction was mixed with $200 \mu \mathrm{l}$ of $125 \mathrm{~mm}$ Tris-HCl (pH 6.8), 4\% SDS, and 10\% 2-ME and kept room temperature for $2 \mathrm{hr}$. The extracts were boiled for 2 min after being mixed with $30 \mu \mathrm{l}$ of glycerol and put into the wells of a slab gel. SDS-PAGE was done by the method of Laemmli $^{77}$ in a $10 \%$ polyacrylamide gel.

Electron microscopy. Fractions of major bands in SDG$\mathrm{UC}$ were washed with homogenizing buffer twice and the precipitate was gelatinized in $2 \%$ LMP agarose (BRL Co., Ltd., $m p=40^{\circ} \mathrm{C}$ ) solution. These fraction gels and intact cotyledons were cut into small pieces with a razor blade, fixed with $5 \%$ glutaraldehyde solution and then with $1 \%$ osmium tetroxide solution (both in $0.1 \mathrm{M}$ cacodylate buffer pH 6.7), dehydrated with a graded alcohol series, and embedded in Spurr resin. The block obtained was sliced and the sections were examined with a transmission electron microscope (JEOL EX1200).

\section{RESULTS}

\section{Distribution of protein and marker enzymes in $S D G-U C$}

Protein contents and marker enzyme activity in SDG-UC fractions are shown in Fig. 1. Two major bands named zone A (fractions $4 \sim 6$ ) and zone B (fractions $11 \sim 13$ ) appeared in the tube. Zone $\mathrm{A}$, with an average density of 1.05 , formed a white band below the soluble fractions, while zone $\mathrm{B}$ formed a green pellet at a density of 1.15. Beside them, lipid bodies floated on the soluble part, starch granules precipitated at the bottom of the tube, and a wide weak band named zone $\mathrm{C}$ (fractions $14 \sim 17)$ appeared below zone $B$.

Zones $\mathrm{A}$ and $\mathrm{B}$ contained equal amounts of protein. Zone A showed high catalase (a marker enzyme for microbodies) activity, 3 times higher than that of zone B. On the other hand, zone $\mathrm{B}$ had high cytochrome $c$ reductase (a marker enzyme for rER) activity, 3 times higher than that of zone A.

These results indicate that microbodies and
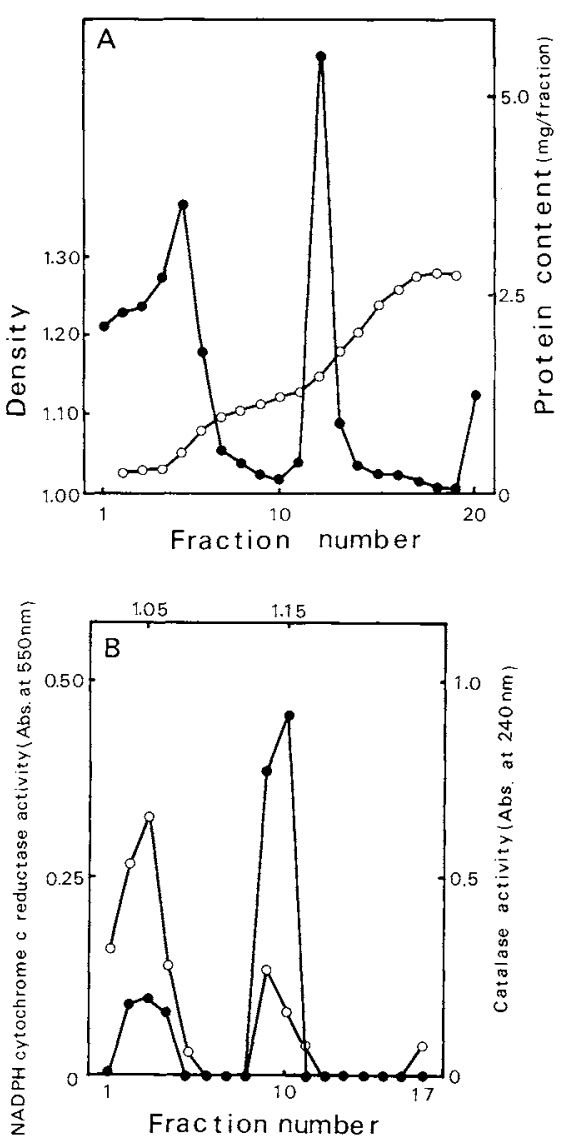

FIG: 1. The Organelles were Separated in the Presence of $5 \mathrm{mM} \mathrm{MgCl}$.

A: Distribution of protein in SDG-UC. protein content; $O$, sucrose density. B: Marker enzyme activities of each fraction. NADPH cytchrome $c$ reductase; $O$, catalase.

rER were partitioned into zone $\mathrm{A}$ and zone B, respectively. Similar results were obtained with cotyledons in more matured stages (at $40 \sim 50$ DAF, data not shown).

\section{Microscopic observation of the fractions and cotyledonary cells}

In Fig. 2 are electron micrographs of zone $\mathrm{A}$, zone $\mathrm{B}$, and intact cotyledonary cells of a developing soybean seed. As we had reported previously, ${ }^{8)}$ in this developing stage, large vacuoles occupied the central portion of cells, and cytoplasm contained ribosomes, Golgi bodies, PLS bodies (organelles found by 

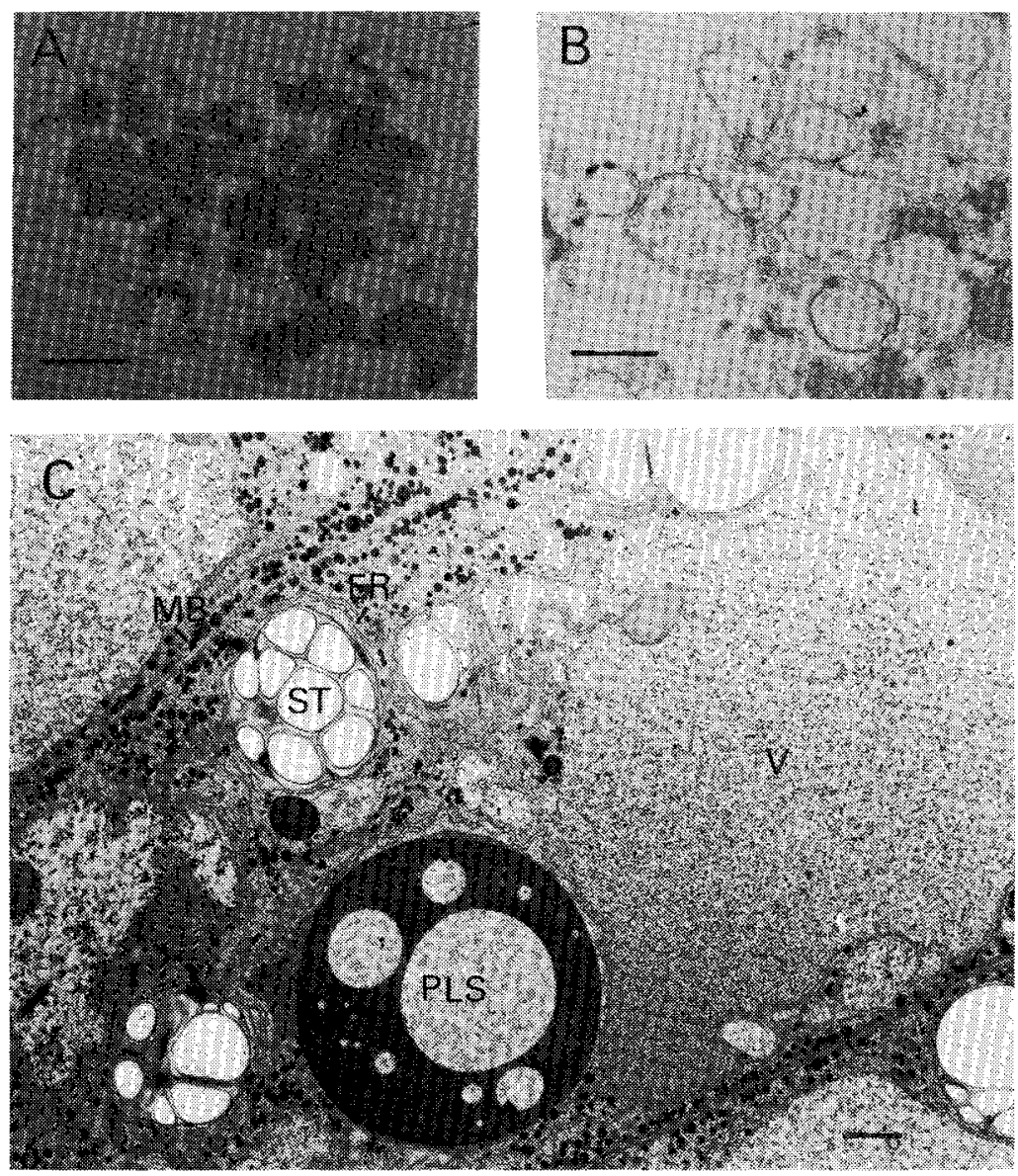

Fig. 2. Transmission Electron Micrographs of Subcellular Fractions Isolated from Developing Soybean Cotyledons and Intact Cotyledon Cells.

A: zone A, microbody-rich fraction, marker $=500 \mathrm{~nm}$. B: zone B, ER-rich fraction, marker $=500 \mathrm{~nm}$. C: developing cotyledon (about $25 \mathrm{DAF}$ ), marker $=2 \mu \mathrm{m}$. V, vacuole; ST, starch granule; MB, microbody; ER, endoplasmic reticulum; PLS, PLS body.

Kaizuma et al. $\left.{ }^{9}\right)$, and plastids with starch granules. Zone A contained mainly microbodies of which the diameter is about $500 \mathrm{~nm}$ and a small amount of membranes. In contrast, zone B consisted mainly of membranes called microsomes.

Figure 3 is a light micrograph of zone $\mathrm{C}$, indicating the presence of large $(5 \sim 10 \mu \mathrm{m})$ vesicles in this fraction.

\section{Polypeptide components of fractionated organelles}

The polypeptide components in the subcellular fractions obtained from SDG-UC were analyzed by SDS-PAGE (Fig. 4). In the homogenate (lane 1), $\alpha$ and $\alpha^{\prime}$ subunits of $\beta$ conglycinin were major and beside them lipoxygenase, the $\beta$-subunit of $\beta$-conglycinin, acidic and basic subunits of glycinin, and several unidentified polypeptides were detected. This SDS-PAGE pattern is similar to that of Yanagi et al. ${ }^{10)}$ where it is shown that $\alpha$ and $\alpha^{\prime}$ subunits of $\beta$-conglycinin were accumulated in advance of glycinin and the $\beta$ subunit of $\beta$-conglycinin. In the soluble fraction (lane 3) and zone A (lanes. 4 and 5), $\alpha$ and $\alpha^{\prime}$ subunits of $\beta$-conglycinin were also the major polypeptides, and an unidentified poly- 


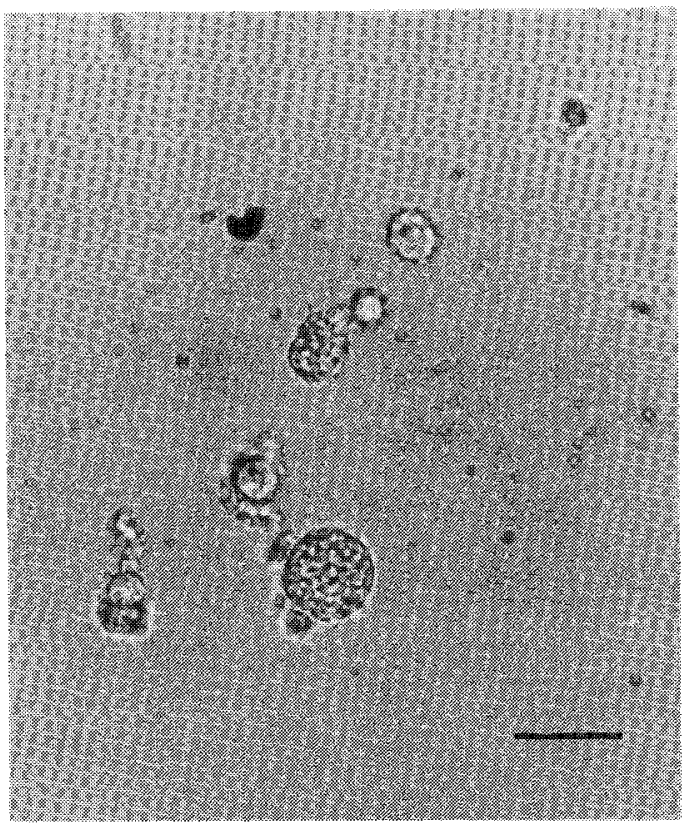

FIG. 3. A Light Micrograph of Vesicles in Zone C.

Marker $=10 \mu \mathrm{m}$.

peptide (band $3, \mathrm{MW}=57,000$ ) was outstanding in these fractions. In zone B (lane 6), the amount of $\beta$-conglycinin and glycinin were roughiy equal. The polypeptides of glycinin were mostly localized in this fraction. Two unidentified bands, band 1 (MW = $69,000)$ and band $2(\mathrm{MW}=60,000)$ were detected in zone B. Zone C (lane 7) contained a small amount of glycinin.

\section{4. $M g$ shift of zone $B$ in $S D G-U C$}

Figure 5 shows the effects of $\mathrm{MgCl}_{2}$ on the SDG-UC profile. In the absence of $\mathrm{MgCl}_{2}$ the density of zone $\mathrm{B}$ decreased to 1.08 (fraction 9 in $\mathrm{A}$ ), while in the presence of $\mathrm{MgCl}_{2}$ it has a density of 1.15 (fraction 14 in $\mathrm{B}$ ). Since the density shift of endoplasmic reticulum has been shown to be the consequence of the deletion of ribosomes from the microsomal vesicles, ${ }^{5}$ this result assured us that the organelles in zone B were rER. The SDS-PAGE pattern of the fractions shows that the storage proteins in zone $B$ were associated with the rER fraction.

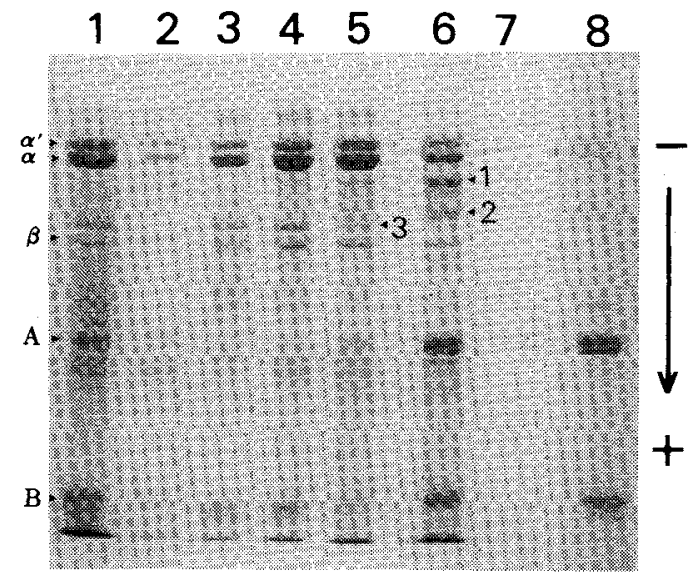

Fig. 4. SDS-PAGE of the Subcellular Fractions Isolated from Developing Soybean Cotyledons.

Lane 1, homogenate applied to SDG-UC; lane 2, top fraction; lane 3, soluble fraction; lane 4, 5, zone A; lane 6 , zone $\mathrm{B}$; lane 7 , zone $\mathrm{C}$; lane 8 , vesicles in zone $\mathrm{C}$ concentrated by centrifugation $(10,000 \mathrm{rpm}, 5 \mathrm{~min}$ by KUBOTA KM-15200). $\alpha, \alpha^{\prime}$, and $\beta$ represent $\alpha, \alpha^{\prime}$, and $\beta$ subunits of $\beta$-conglycinin. $A$ and $B$ represent acidic and basic subunits of glycinin, respectively. Band $1 \sim 3$ are unidentified polypeptides, MW of band 1, 2, and 3 were $69,000,60,000$, and 57,000 , respectively.

\section{DISCUSSION}

The data reported here indicate the difference of subcellular localization between the two major storage proteins, $\beta$-conglycinin and glycinin, during the mid-development stage of soybean seeds. From the distribution of marker enzymes, electron microscopic observation, and the effects of $\mathrm{MgCl}_{2}$, two main bands in SDG-UC, zone A and B, were identified as the microbody fraction and $r E R$ fraction, respectively. The amounts of $\beta$-conglycinin and glycinin associated with rER were roughly equal. In the microbody fraction and soluble fraction, which may be derived from cytosol and vacuoles, $\alpha$ and $\alpha^{\prime}$ subunits of $\beta$ conglycinin were the only major polypeptides. It is noted that $\beta$-conglycinin was found in soluble and microbody fractions as well as rER fraction, while glycinin was mostly localized in $\mathrm{rER}$ and partly in the vesicles found in zone C.

The association of $\beta$-conglycinin and glyci- 

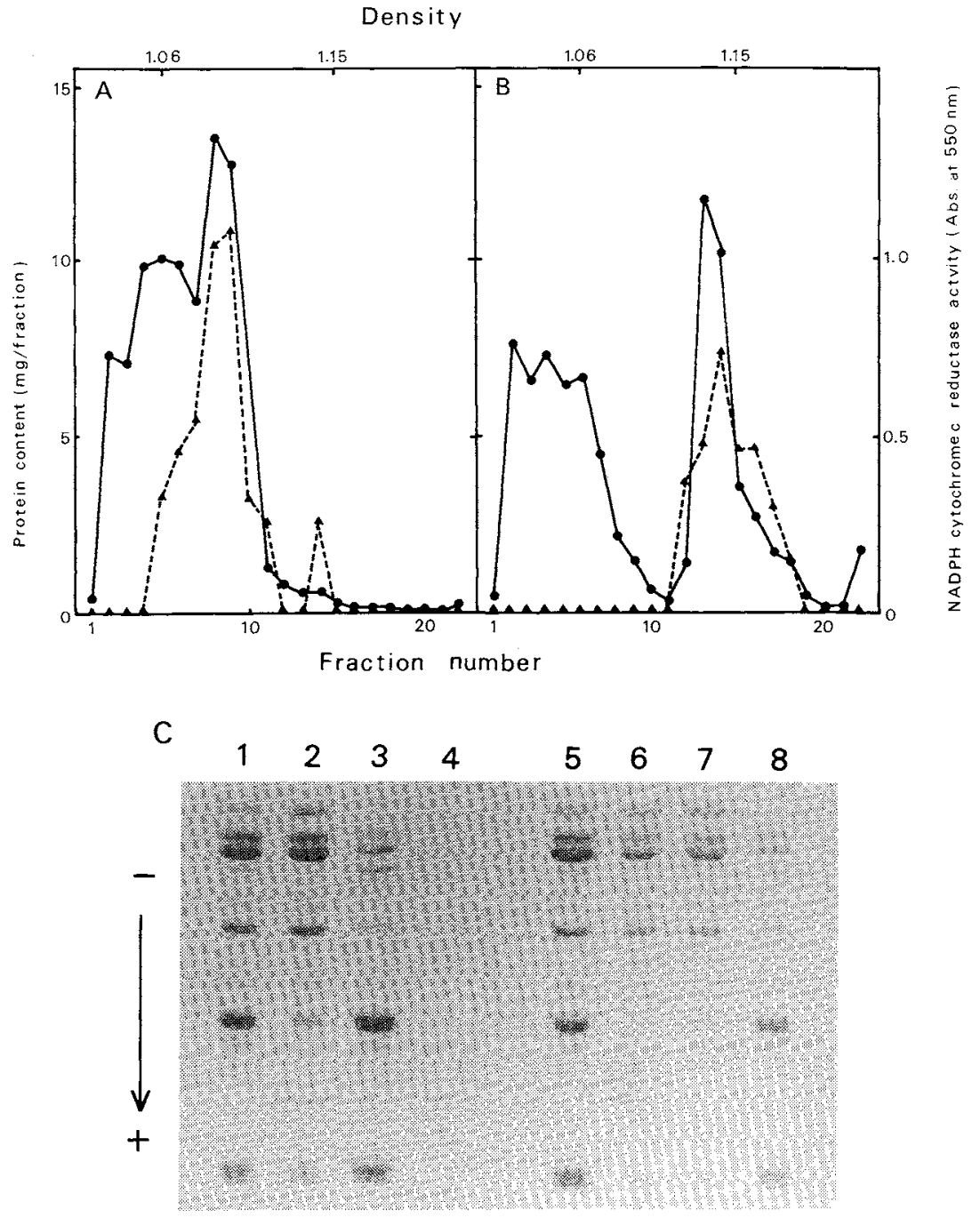

FIG. 5. Shift of Zone $\mathrm{B}$ in SDG-UC by $\mathrm{Mg}^{2+}$.

A: $-\mathrm{MgCl}_{2}$. B: $+5 \mathrm{mM} \mathrm{MgCl}_{2}$. , protein content; $\boldsymbol{\Delta}$, NADPH cytochrome $c$ reductase C: SDS-PAGE of the subcellular fractions. Lane $1 \sim 4$ and lane $5 \sim 8$, fractions from SDG-UC of A and B, respectively; lane 1 and 5, homogenates applied for SDG-UC of A and B, respectively; lane 2, 3 and 4, fraction 3, 9 and 14 in A; lane 6,7 and 8 , fraction 3,6 and 14 in $\mathrm{B}$.

nin with the rER fraction implies that these proteins are temporary deposited within the cisternae of $r E R$ after biosynthesis and cotranslational processing.

Komatsuda et al. ${ }^{11)}$ showed immunocytologically the presence of $\beta$-conglycinin in the vacuoles in developing soybean cotyledons using a fluorescence microscope. Based on their study, we ascribed $\beta$-conglycinin found in the soluble fraction to vacuoles. It was also reported that protein bodies in soybean cotyledons originate from vacuoles. ${ }^{12)}$

It was interesting that the appearance of the microbody fraction in our experiments are similar to that of the small electron-dense vesicles $(0.1 \sim 0.4 \mu \mathrm{m})$ fractionated from Phaseolus vulgaris by Chrispeels. ${ }^{13)}$ He showed that these vesicles are involved in the transportation of phaseolin (a $\beta$-conglycinin related glycoprotein in Phaseolus vulgaris) from Golgi 
bodies to protein bodies. The $\alpha$ and $\alpha^{\prime}$ subunits of $\beta$-conglycinin were the only major polypeptides in the microbody fraction in this study. Ladin et al. ${ }^{14)}$ observed that electron-dense small vesicles bud from or are associated with the Golgi bodies also in developing soybean cotyledons.

To explain the difference in intracellular distribution between $\beta$-conglycinin and glycinin, we assume that these storage proteins synthesized at $\mathrm{rER}$ are transported through or temporary deposited in different sites of developing cotyledonary cells. That is, vacuoles and microbodies are involved in the intracellular transportation of $\beta$-conglycinin, and large dense vesicles which appeared at the density of $1.20 \sim 1.25$ (zone $C$ ) have to do with that of glycinin.

\section{REFERENCES}

1) K. Saio and T. Watanabe, Agric. Biol. Chem., 30 ,
1133 (1966).

2) N. E. Tumer, V. H. Thanh and N. C. Nielsen, J. Biol. Chem., 256, 8756 (1981).

3) R. N. Beachy, Plant Physiol., 65, 990 (1980).

4) M. M. Bradford, Anal. Biochem., 72, 248 (1976).

5) J. M. Lord, T. Kagawa, T. S. Moore and H. Beevers, J. Cell Biol., 57, 659 (1973).

6) H. Aebi, "Methods of Enzymatic Analysis," 2nd Ed., Academic Press, New York, 1974, pp. $643 \sim 684$.

7) U. K. Laemmli, Nature, 227, 680 (1970).

8) K. Saio, K. Kondo and T. Sugimoto, Food Microstructure, 4, 191 (1985).

9) N. Kaizuma and A. Kasai, Japan. J. Breed., 31 (suppl. 1), 223 (1981).

10) S. O. Yanagi, C. Fukazawa and K. Harada, Agric. Biol. Chem., 42, 697 (1978).

11) T. Komatsuda, N. Kaizuma and K. Kitamura, personal communication.

12) B. Y. Yoo and M. J. Chrispeels, Protoplasma, 103, 201 (1980).

13) M. J. Chrispeels, Planta, 158, 140 (1983).

14) B. F. Ladin, M. L. Tierny, D. W. Meinke, P. Hosagadi, M. Veith and R. N.'Beachy, Plant Physiol., 84, 35 (1987). 